\title{
Reproductive Strategies Change With Time in a Newly Founded Colony of Spotless Starlings (Sturnus unicolor)
}

\author{
Patricia Celis $^{1 *}$, Jeff A. Graves ${ }^{2}$ and Diego Gil ${ }^{3}$ \\ ${ }^{1}$ School of Life Sciences, Anglia Ruskin University, Cambridge, United Kingdom, ${ }^{2}$ School of Biology, Harold Mitchell \\ Building, University of St Andrews, St Andrews, United Kingdom, ${ }^{3}$ Departamento de Ecología Evolutiva, Museo Nacional \\ de Ciencias Naturales (CSIC), Madrid, Spain
}

OPEN ACCESS

Edited by:

Ann Valerie Hedrick, University of California, Davis,

United States

Reviewed by:

Juan Gallego Rubalcaba,

McGill University, Canada

Gustavo Tomás,

Estacion Experimental de Zonas

Aridas (EEZA), Spain

*Correspondence:

Patricia Celis

Paty.Celis@aru.ac.uk

Specialty section:

This article was submitted to Behavioral and Evolutionary Ecology,

a section of the journal

Frontiers in Ecology and Evolution

Received: 26 January 2021 Accepted: 07 April 2021

Published: 07 May 2021

Citation:

Celis P, Graves JA and Gil D

(2021) Reproductive Strategies

Change With Time in a Newly Founded Colony of Spotless Starlings

(Sturnus unicolor).

Front. Ecol. Evol. 9:658729.

doi: 10.3389/fevo.2021.658729
Variation in avian reproductive strategies is often studied from a comparative perspective, since even closely-related taxa differ greatly in the degree of polygyny, extra-pair paternity (EPP) or intra-specific brood-parasitism. However, substantial variation at the species level suggests that ecological factors are important in shaping these patterns. In this study, we examined the temporal plasticity of these strategies, following a population from the year of colony formation to 2 years after this. Parentage data from these years shows that polygyny decreased with time, likely as a consequence of increased competition for nesting sites and mates by new recruits, and immigrants of higher quality arriving to the colony as time passed. In parallel to this temporal change, we found an increase in intra-specific brood-parasitism and quasi-parasitism (QP). We interpret these patterns as a consequence of an increase of floaters with time; these birds pursue a mixture of alternative mating strategies to succeed in the population. We also found evidence of conspecific brood parasitism (CBP), by nesting females that laid part of the clutch in another nest or that after losing a partially laid clutch resorted to lay the last eggs in another nest. Analyses of the distance between the main nest and nests containing the secondary polygynous brood or extra-pair or parasitic young showed an avoidance of contiguous nests for conducting these alternative reproductive tactics. At the same time, these secondary nests were closer to the main nest than random distances within the colony, suggesting that access to public information was restricted to a narrow area around the main nest. Our study emphasizes how behavioral patterns are plastic traits that vary not only with individual circumstances, but also with time, tracking changes in density and social structure.

Keywords: extra-pair paternity, intraspecific brood parasitism, quasi-parasitism, density, birds, floaters, Sturnus unicolor, alternative reproductive strategies

\section{INTRODUCTION}

The development of molecular techniques to assign parentage has resulted in a shift in our view of birds' reproductive behavior by providing evidence of the prevalence of alternative reproductive strategies (Birkhead and Møller, 1998; Jones and Ardren, 2003; Griffith et al., 2004) such as extrapair paternity (EPP), conspecific brood parasitism $(\mathrm{CBP})$, and quasi-parasitism $(\mathrm{QP})$. This change 
of perspective can be duly appreciated if we compare it to our state of knowledge in the 1960s. For instance, Lack (1968) reported that $93 \%$ of passerine subfamilies were monogamous with strong pair associations, a scenario which left no room for extra-pair copulations. In striking contrast, more recent estimates suggest that $75 \%$ of all the bird species studied so far exhibit EPP (Brouwer and Griffith, 2019).

The incidence of EPP varies greatly within and between species. For some species EPP has not been detected while for others over $88 \%$ of the nests have been found to contain extra-pair young (EPY) (Brouwer and Griffith, 2019). The ecological basis of this great variation in EPP rate has been of research interest for over two decades, but is far from being understood (Petrie and Kempenaers, 1998; Arnold and Owens, 2002; Westneat and Stewart, 2003; Brouwer and Griffith, 2019). Studies show that EPP rates are higher in species in which the adult mortality is higher and the amount of paternal care is lower; this points towards a decrease in the risk of retaliation and, consequently, a decrease in the potential costs of EPP (Arnold and Owens, 2002). In addition, one of the traditional explanations for the observed differences in EPP rate is density dependence (Westneat and Sherman, 1997; Griffith et al., 2002). Although little evidence has been found for the density hypothesis when looking at differences between species, stronger evidence has been found for within-species variation dependence (Westneat and Sherman, 1997; Griffith et al., 2002; Mayer and Pasinelli, 2013). Although very few studies have manipulated putative correlates of EPP at the population level (Brouwer and Griffith, 2019), the high levels of variance at the species level suggest that this type of approaches may prove useful in understanding the complexity of the phenomenon. In this study, we indirectly assess the density dependence hypothesis by evaluating the incidence of EPP during the first 3 years after the establishment of the colony. We are not aware of any other studies in which this comparison has been performed.

Conspecific brood parasitism has been detected in over 250 bird species (Yom-Tov and Geffen, 2017). The use of CBP as a reproductive strategy is more common in species with precocial offspring, high fecundity and relatively inexpensive parental care, as well as in hole-nesting species (Geffen and Yom-Tov, 2001; Arnold and Owens, 2002; Yom-Tov and Geffen, 2017). Four different hypotheses have been proposed to explain the adaptive basis of CBP (Petrie and Møller, 1991; Lyon and Eadie, 2008, 2017). (1) CBP is performed by "lifelong specialist parasites" (i.e., females that do not ever have their own nest and, therefore, depend completely on CBP to reproduce). (2) CBP is used as a "best of a bad job" strategy by females that are unable to nest by themselves (floaters) because of a limitation of resources (e.g., limited nest sites). (3) CBP is a response to "nest loss," where some females may resort to laying the rest of a clutch in the nests of other females after the loss of the initial partially-laid clutch (e.g., due to predation or sabotage by other individuals of the same-species). (4) CBP is a "side payment" or "reproductive enhancement," where females that have their own nests lay eggs also in other nests to enhance their fecundity while limiting their parental investment to the offspring in their own nest. The first two hypotheses aim to explain CBP by a female that does not have a nest of her own (floater), while the last two aim to explain
CBP by nesting females. Even though many studies have reported the existence of contrasting levels of CBP in different species and populations, fewer studies have been able to detect the identity of the parasitic female and provide support for any of these hypotheses (Lyon and Eadie, 2008, 2017). In a recent review, this information was only available for 56 of the 256 species for which CBP has been reported (Lyon and Eadie, 2017). No evidence has been found supporting the first hypothesis ("lifelong specialist parasites"), while some studies have found evidence for the remaining hypotheses, often with data supporting more than one of them in the same species (Yom-Tov and Geffen, 2017). For example, CBP seems to be a strategy used by floaters in the European starling (Sturnus vulgaris; Eadie and Fryxell, 1992; Sandell and Diemer, 1999) but CBP has also been induced by the experimental destruction of partial clutches (Stouffer et al., 1987; Feare, 1991). By combining observational data and genetic parentage assignment, we aim, not only to detect the incidence and change of CBP through time, but also to find the evidence supporting some of the adaptive basis of CBP hypotheses.

Quasi-parasitism occurs when a parasitic egg is fertilized by the host-male (the social mate of the host-female) and is laid in the nest of the host-female. Even though parasitic females may gain genetic benefits from QP (e.g., avoiding inbreeding and increasing genetic variation of their chicks), the main benefits for the parasitic female seem to be an increase in the access to host-nests to lay the parasitic egg (Griffith et al., 2004). The cost and benefits for males fathering QP offspring vary depending on the reproductive status of the females. Greater potential benefits are predicted for the fathers of QP offspring when the parasitic females also have their own nest, since their chances to sire EPY with this females increases (Berger et al., 2014).

Quasi-parasitism has been reported in only a few bird species, and at very low frequency (Griffith et al., 2004; Lyon and Eadie, 2008). For QP to be considered a reproductive strategy per se, a female needs to gain access to the host nest in exchange for copulations with the host-male. It is not clear if QP really exists in these species as a reproductive strategy or if it is just an artifact of other reproductive tactics such as high levels of CBP, EPP and rapid mate switching (Griffith et al., 2004; Lyon and Eadie, 2008). In the case of the barn swallow (Hirundo rustica), it has been found that QP can serve as an enhancement of male and female breeding success, being performed by females that breed elsewhere (Petrželková et al., 2015). However, it is also possible that female floaters associate with a given male and, eventually, take over as primary females. One of the aims of this study is to combine the genetic data with the observational to try to determine which adaptive base or basis QP may have in the spotless starling; and whether QP is a reproductive strategy per se or an artifact in this species.

Mating strategies are almost invariably the result of a compromise between benefits and costs (Slagsvold and Lifjeld, 1994). In the case of males, prolonged absence from the nest site may result in losing it to floaters. On the other hand, starlings trying to attract a second female too close to the nest of the primary mate may lead to aggression between females, possibly resulting in losing the second female (Sandell and Smith, 1996) or delaying its reproduction (Sandell, 1998). Thus, it is to be 
expected that the optimal distance between the primary and the secondary nest of the same male is small, but no too close either (Sandell and Smith, 1996). A similar constraint may appear in the search for extra-pair copulations (EPC), in which far away forays may lead to the main nest remaining unwatched, and close-by EPCs may result in fights with the cuckolded male (Birkhead and Møller, 1998).

Another reproductive decision is whether to mate with the same partner in subsequent reproductive attempts. For birds, the term "divorce" has been used to describe a change of breeding partner when both partners are still alive; this contrasts to "widowing" when one of the partners has died (Culina et al., 2015). Divorce could be an adaptive strategy if an individual expects to get a better quality mate (the better option hypothesis: Baeyens, 1981; Ens et al., 1993) or a more compatible one (i.e., a mate with characteristics that combined with those of that individual will enhance their fitness; the incompatibility hypothesis: Coulson, 1966; Dubois and Cézilly, 2002). Alternatively, the change may be forced on the individual, for example as a result of intra-sexual competition (e.g., nest usurpation) or as a consequence of a low probability of reencountering a mate (Culina et al., 2015). Divorce between reproductive seasons and, to a lesser extent, within seasons ("rapid mate switching") has been widely studied in social monogamous birds (Jacot et al., 2010) but there are few studies in polygynous species. Even though individual studies have not always found evidence supporting divorce as an adaptive strategy, meta-analyses of the available studies in monogamous birds support this hypothesis (Dubois and Cézilly, 2002; Culina et al., 2015). Culina et al. (2015) found that, even though the reproductive success of divorcees and widows was lower than that of faithful pairs, divorcees experienced a higher reproductive success after divorcing than they had with the previous mate. Meta-analyses have also shown that females benefit from divorce while no benefit was found for males (Dubois and Cézilly, 2002; Culina et al., 2015).

The spotless starling (Sturnus unicolor) is a hole-nesting, facultatively polygynous species, mainly confined to the Iberian Peninsula and North Africa (Aparicio et al., 2001; Cordero et al., 2001). In high density nesting colonies, males attempt to defend several nest-sites, which limits the recruitment of other individuals to the colony (Cordero et al., 2001). Feeding territories are communal and only nest-sites are defended against conspecifics (Veiga et al., 2001). Previous studies report polygyny levels of up to four females per male, with between 75 and $94 \%$ of the males being polygynous (Cordero et al., 2003, 2004). However, long-term studies suggest that these high levels may be artifacts of newly established nest-box colonies and that monogamy is the commonest strategy once the populations are well established (Gil, D., per. obs.). This species exhibits high levels of philopatry in the populations in which they have been studied and is relatively long-lived. Spotless starlings reproduce synchronously with neighbors in the colony. They often have two consecutive clutches per year, in which females lay around five eggs per clutch. In case of failure of the first clutch, a replacement clutch is laid. Given the high laying synchrony found in this population, we refer to these peaks of laying as first, intermediate and second clutches. In central Spain, the first clutch is typically laid in April and the second clutch is laid between May and June.

Reported levels of EPP and CBP vary between populations in the same year and also for the same populations in different years (Calvo et al., 2000; Cordero et al., 2003). Cordero et al. (2003) used multi-locus DNA fingerprinting to determine parentage in the spotless starling and found a high level of EPP. Depending on the year, this study showed that between 10 and $20 \%$ of chicks were the result of EPP. They also reported one instance of CBP and one of QP out of the 334 chicks studied. A previous study (Calvo et al., 2000) reported a much higher incidence of CBP, with more than $35 \%$ of the first clutches and between 12 and $20 \%$ of intermediate and second clutches containing a parasitic chick. However, this study was based solely on observational data (differences in egg color and size or the appearance of two newlylaid eggs on the same day) making it impossible to differentiate between CBP and QP. In a later study, García-Vigón et al. (2008) used six microsatellites to assess parentage and detected in the control group that $15.3 \%$ of chicks were extra-pair young (EPY). They also detected two cases of QP but did not detect any cases of CBP within their sample ( $n=364$ chicks).

In this study we used nine microsatellite loci to genotype 1,225 offspring and 317 adult spotless starlings, together with observational data to identify the parentage of the offspring, with the aim of detecting EPP, CBP, and QP. The resolution of these genetic markers offers the potential to detect not only the existence and level of EPP, CBP, and QP in this species but also to identify the true parents exhibiting these reproductive tactics with high confidence. We were also able to identify cases of mate retention vs. mate switching within and between seasons and to calculate levels of polygyny. We conducted this study for 3 years right after the nest-box colony was started, allowing us to analyze how paternity patterns changed after the colony was set and the population dynamics changed with the increase in available partners. Although this is not a deliberate experiment, it allows us a rare glimpse into how population changes affect reproductive patterns within a population.

\section{MATERIALS AND METHODS}

The study was done in a nest-box colony in a dehesa communal woodland in Soto del Real $\left(40^{\circ} 45^{\prime} 15^{\prime \prime} \mathrm{N} ; 3^{\circ} 47^{\prime} 00^{\prime \prime} \mathrm{W}\right)$, located in central Spain. Field work extended for three seasons, between March and July of 2004, 2005, and 2006. Several months before the 2004 field season, 78 nest boxes were placed at the study site, in groups of three nest-boxes. Within a group, nest-boxes were placed at $16.95 \mathrm{~m}(\mathrm{SD}=5.24)$ from each other. Groups were separated from each other at a far greater distance; the mean minimum distance between groups was $83.33 \mathrm{~m}$ ( $\mathrm{SD}=17.44$; Figure 1). The field site is an open forest with some areas of pasture used for cattle grazing. The predominant trees in the area are ash (Fraxinus angustifolius) and oak (Quercus pyrenaica). We do not have a precise estimation of the numbers of birds nesting in natural holes before the nest-box colony was erected, although anecdotal data suggest that the number was small, nor greater than one natural nest per six nest-boxes. This means that the 


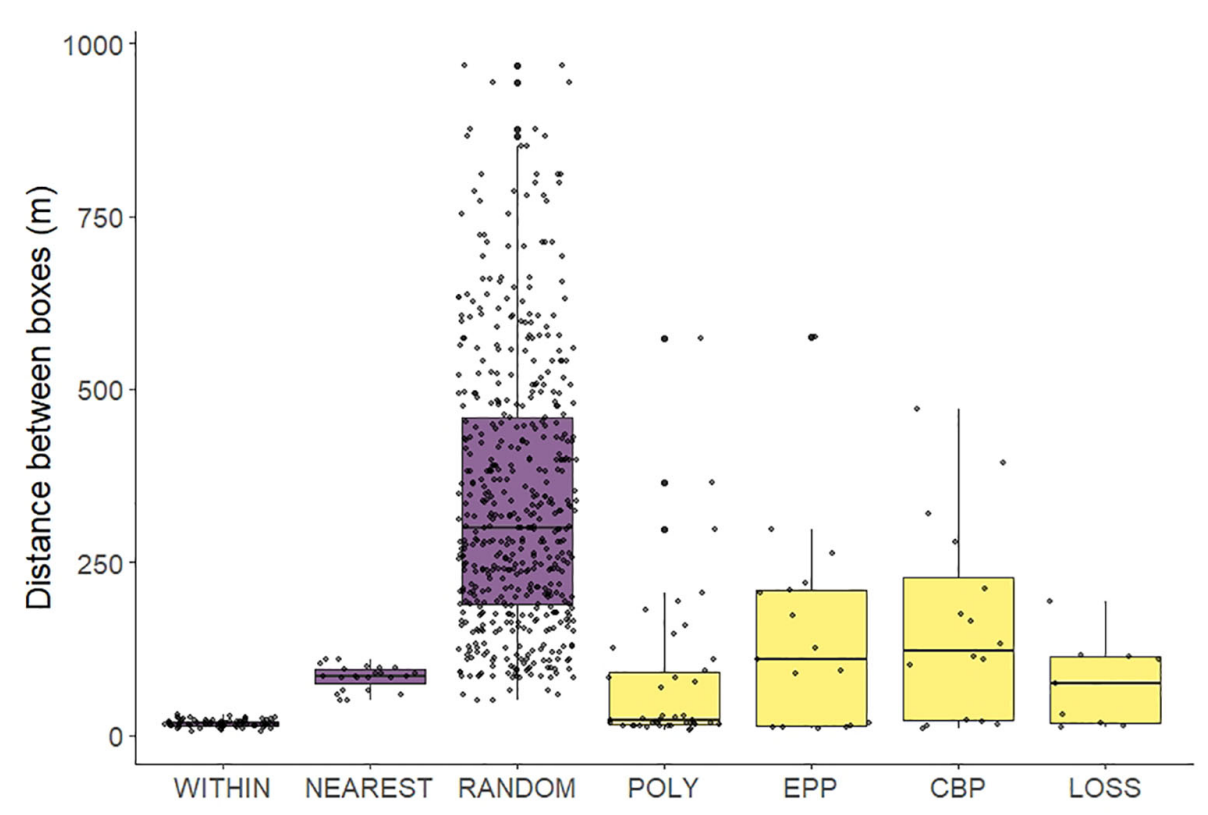

FIGURE 1 | Boxplot of distances between different nest boxes. For comparison, in mauve we represent map-derived distributions of distances within the same trio (within), between boxes at the nearest trio (nearest) and between all boxes (random). In yellow we plot distances between nests fathered by the same male: distances between the two nests of the same polygynous males (poly), between the main nest and the nest where EPY was detected (EPP), and between the main nest and the nest where CBP was identified (CBP). Finally, for females that became parasitic after losing a nest, we plot the distance between the lost nest and the nest in which the parasitic eggs were laid (LOSS).

breeding population density became at least six times greater after the boxes were added to the forest. Birds nesting in natural holes could not be caught except when they were exploring nest-boxes, and we cannot distinguish them from floaters.

Adults were captured inside the nest boxes using a spring trap. Captures were done before egg-laying started or when the offspring were between four and 11 days old, to minimize abandonment resulting from the disturbance. During captures adults were tagged using a unique combination of plastic colored leg-rings and a numbered aluminum leg-ring. We also recorded basic morphometric measurements: body mass was taken with a digital balance (Ohaus, United States) to the nearest $0.1 \mathrm{~mm}$, wing length was measured with a ruler to the nearest $\mathrm{mm}$, and tarsus length with digital calipers (Mitutoyo, Japan) to the nearest $0.1 \mathrm{~mm}$. In addition, a blood sample from the brachial vein and four ornamental feathers from the central part of the chest were taken. Feathers were measured from the tip of the vanes to the end of the calamus using digital calipers to the nearest $0.01 \mathrm{~mm}$. The mean of the three longest feathers, out of four, was used to avoid underestimation due to artificially shortened feathers. Repeatability of this measurement was very high $[\mathrm{D}=358, R=0.76, \mathrm{SE}=0.028, \mathrm{CI}=(0.701,0.812)$, $P<0.001]$. The natural logarithm of the males' tarsus length and wing length was used in a principle component analysis and the first principle component was used as a measurement of male body size (PC1 eigenvalue $=1.1$, variable loadings: 0.71 for both measurements). In total, 165 male and 204 female adult birds were captured and from these blood samples were obtained from 154 males and 188 females. For an associated study, in
2005 and 2006 some of the males that were captured (17 and 25 males, in 2005 and 2016 respectively), were subjected to a treatment to alter the length of their throat ornamental feathers. The treatment had no significant effect on the reproductive status (i.e., not reproducing, monogamous or polygynous), number of offspring sired or loss of paternity (Celis et al., in preparation) and are therefore included in this study.

When the chicks were 6 days old they were ringed, measured and a blood sample was taken. A tissue sample was taken from embryos of un-hatched eggs and from any chick that died before the seventh day. In total, samples were collected from 1,244 offspring during the 3 years. All the blood and tissue samples were kept in $0.5 \mathrm{ml}$ buffer ( $100 \mathrm{mM}$ TRIS, $\mathrm{pH}=8.5 ; 100 \mathrm{mM}$ EDTA, $\mathrm{pH}=8.5 ; 2 \% \mathrm{SDS}$ ), stored for up to 6 months at room temperature and then at $-20^{\circ} \mathrm{C}$.

Nest boxes were checked regularly to determine laying-date, clutch size, and hatching date. After hatching, observations were made to record which adults visited the nest boxes, and these were assigned as the most probable social parents of the broods within. In 2004, 43 nests boxes were observed from a temporary hide, using a telescope. During 2005, all the nest boxes that contained chicks were observed using video cameras. However, in 2006, only nest boxes that contained chicks in the first clutches were recorded. The identity of all adults that were observed going inside or close to the focal nest was determined by their unique combination of color rings. To determine the most likely social parents the adults that were originally trapped in the box and adults seen during nests revisions were also considered. 
DNA was extracted from blood samples of adults and chicks using the PUREGENE protocol (Gentra Systems). Genotypes were obtained for nine highly polymorphic microsatellite loci: Pca7 (Dawson et al., 2000); FhU2 (Primmer et al., 1996); Sta308, Sta269, Sta97, Sta294, Sta296, Sta213, and Sta70 (Celis et al., 2007), following the protocols in Celis et al. (2007). Genotypes were obtained for 317 adults (171 females and 146 males) and 1,225 offspring. The mean $( \pm S D)$ number of amplified loci was $8.4 \pm 2.0$ per individual for the adults $(8.3 \pm 2.2$ and $8.4 \pm 1.8$ for females and males respectively) and $7.9 \pm 1.8$ for the offspring.

The characteristics of the microsatellites were assessed (Table 1). Three of the loci were not in HWE. The analysis in both NEWPAT and CERVUS, revealed high levels of null alleles for these three loci (from 10 to $37 \%$ ). In addition, another locus (Sta97) is sex linked (on the Z chromosome). Neither CERVUS 3.0.3 nor NEWPAT XL is able to deal with sex-linked loci. Since one of the microsatellite loci is sex-linked, values of this locus were excluded for all the females (chicks and adults). Therefore, all females were presented as un-scored for that locus, and only males' values were used.

Data were checked for duplicate entries (Identity checking) using NEWPAT XL (Summers and Amos, 1997; Wilmer et al., 1999) and CERVUS 3.0.3 (Marshall et al., 1998; Kalinowski et al., 2007). Both programs detected two cases in which a pair of siblings had the same genotype and a case where a pair of siblings had identical genotypes except for one allele. There was no instance of two adults sharing the same genotype.

Data were checked for mismatches between the observed or captured mothers and the chicks, using NEWPAT XL. When a genuine mismatch was detected (i.e., not due to null alleles) the results from the other chicks of the nest were used to infer if the chick was parasitic or if the observed female was not the mother of that brood. In these cases, the chicks were analyzed for paternity without a known mother. Parentage was assessed, first using NEWPAT XL (Summers and Amos, 1997; Wilmer et al., 1999), and then using CERVUS 3.0.3 (Kalinowski et al., 2007).

Since NEWPAT XL was designed to obtain paternities, to find both parents, data had to be analyzed in different runs to find the father and then the mother (if unknown). The analysis parameters were set as follows: maximum number of mismatching loci allowed $=1$; minimum acceptable probability for a match containing null alleles $=0.05$; number of un-scored loci allowed for paternity was first set to two, in the first run of analysis; and then to four, in the second one. Only paternity not assigned in the first analysis was ran in the second; allowing the inclusion of individuals with more incomplete genotypes (both chicks and adults).

The parents identified from the NEWPAT analysis were only accepted if this genetic assignment was confirmed using observational data (male observed or captured in the area) or if they genetically matched three or more chicks in the brood, given that it is highly improbable that this would have occurred by chance. Where an incomplete offspring genotype impeded NEWPAT's parentage analysis, the candidate father shared by most chicks in the brood was accepted as the true father if it was consistent with the inferred paternal genotype at the loci available. Once paternity was assigned, NEWPAT XL was run again to assign maternity. The same parameters were used for running the program and the same criteria were used in interpreting the output.

The results obtained with NEWPAT were checked using CERVUS. Since CERVUS cannot handle null allele frequencies higher than $5 \%$, the data were modified to improve the way CERVUS dealt with the null alleles. A "dummy" allele was created for the three loci with higher rates of null alleles, and then all the homozygotes for these loci were converted to heterozygotes, substituting one of the homozygous alleles with the dummy, following Jones and Ardren (2003).

The parentage analysis in CERVUS was done following the same procedure as in NEWPAT: first the paternity was analyzed with known mothers (if available) followed by the maternity analysis (with known fathers). All parameters established in CERVUS were set as follows and conserved in the different analyses: the proportion of parents sampled was set to $80 \%$; the proportion of mistyped loci to $1 \%$; the minimum number of typed loci to 5; and the confidence parameters to $80 \%$ (relaxed) and to $95 \%$ (strict).

From a total of 1,225 genotyped offspring from the three field seasons at least one parent was assigned to 1,042 offspring $(85.06 \%)$. Both parents were assigned to $690(56.32 \%)$. For

TABLE 1 | Characteristics of nine microsatellite loci amplified for 184 adult spotless starlings.

\begin{tabular}{|c|c|c|c|c|c|c|c|}
\hline Locus & No. of alleles & Product size range & $\mathbf{H}_{\mathrm{e}}$ & $\mathbf{H}_{0}$ & $\boldsymbol{P}$ value(HWE) & Proportion of null alleles & GenBank Access. No. \\
\hline Sta308 & 14 & $130-154$ & 0.90 & 0.89 & 0.373 & $0.01^{d} 0.01^{e}$ & DQ860237 \\
\hline Sta269 & 14 & $181-211$ & 0.85 & 0.84 & 0.315 & $0.003^{d} 0.003^{e}$ & DQ860238 \\
\hline Sta97 ${ }^{a}$ & 7 & $237-251$ & $0.72^{b}$ & $0.78^{b}$ & $0.715^{\mathrm{b}}$ & $-0.047^{\mathrm{b}, \mathrm{d}} 0.003^{\mathrm{b}, \mathrm{e}}$ & DQ860239 \\
\hline Sta294 & 9 & 293-309 & 0.73 & 0.78 & 0.22 & $-0.042^{\mathrm{d}} 0.003^{\mathrm{e}}$ & DQ860240 \\
\hline Sta296 & 9 & $314-330$ & 0.74 & 0.72 & 0.085 & $0.011^{d} 0.011^{e}$ & DQ860241 \\
\hline Sta213 & 17 & $155-228$ & 0.85 & 0.53 & $<0.001^{\star}$ & $0.224^{\mathrm{d}} 0.224^{\mathrm{e}}$ & DQ860242 \\
\hline Sta70 & 13 & $224-264$ & 0.72 & 0.33 & $<0.001^{\star}$ & $0.376^{d} 0.376^{e}$ & DQ860243 \\
\hline $\mathrm{PCA} 7^{\mathrm{C}}$ & 10 & $90-126$ & 0.53 & 0.43 & $<0.001^{*}$ & $0.101^{d} 0.101^{e}$ & - \\
\hline FhU2 ${ }^{\mathrm{c}}$ & 12 & $118-151$ & 0.80 & 0.81 & 0.309 & $-0.009^{d} 0.003^{e}$ & - \\
\hline
\end{tabular}

$H_{e}$, expected heterozygosity; $H_{0}$, observed heterozygosity.

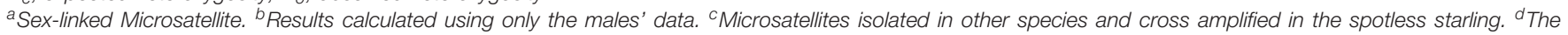
proportion of null alleles calculated, using CERVUS 3.0.3 (Marshall et al., 1998). ${ }^{\circledR}$ The proportion of null alleles calculated, using NEWPAT XL (Wilmer et al., 1999). 
188 offspring (15.35\%) just the mother was found and for 164 (13.39\%) just the father.

Parentage results obtained using CERVUS and NEWPAT were similar. From the 1,552 parents assigned by NEWPAT, just $75(4.83 \%)$ were not found using CERVUS. In most of these instances the substitution of true alleles by dummy ones (for dealing with null alleles) seemed to be causing false mismatches. In $1,280(82.47 \%)$ cases the parentage was assigned to the individual with the highest LOD score (NEWPAT output). Of the parents assigned by both programs and confirmed with observational data, $973(65.88 \%)$ were assigned with more than $80 \%$ confidence, while 615 (41.64\%) were assigned with a confidence greater than $95 \%$ by CERVUS. 345 out of $1,318(26.18 \%)$ of the parents assigned by CERVUS with $80 \%$ confidence were rejected due to the lack of supporting observational data. The same was true for 76 out of $691(11.00 \%)$ of the parents assigned with $95 \%$ confidence.

Statistical analyses were conducted in R (R Core Team, 2019). Chi-squared tests were used to assess differences in percentages between years. We used the package lme4 for linear models, and rptR for repeatability estimates (Stoffel et al., 2017). We assessed differences in distance between breeding categories by bootstrapping with replacement (10,000 resamples) from the half matrix of distances between all boxes involved, and calculating the percentage of cases in which the median of the observed data was smaller than the resampled medians (percentile method).

\section{Bioethics}

Permission to work in the area, capture birds and collect blood samples was granted by permits from the Parque Regional del Alto Manzanares (Consejería de Medio Ambiente de la Comunidad Autónoma de Madrid) (Ref. 10/129049.9/11) and the city council of Soto del Real. At the time of this study (2004-2006) our manipulation did not require an experimentation permit under Spanish law.

\section{RESULTS}

\section{Social Pairs}

In the 3 years of study, there was a total of 127 occasions in which nests contained more than one clutch per year. Sufficient data were available from 116 of these nests to determine if the parents in the first clutch were the same as in the second clutch. A total of 57 (49\%) nests exhibited changes of at least one parent from the first clutch to the second within years. Females were more than twice as likely to change as males (23 vs. 10 detected cases), while 24 changes of both parents were detected.

During the 3 years of the study, 234 different adults were assigned as parents in the population (109 males and 125 females). From those, 112 individuals (50 females and 62 males) produced offspring in more than 1 year, but just 19 pairs remained together for 2 years and none stayed together for all 3 years. Of these permanent pairs, most (16) sired whole broods in both years. However, three of these pairs produced just one EPY or a QP chick in one of the years and a complete brood in the other (Table 2).
Seventeen of the 176 females that were assigned as the main mother of a clutch, also mothered CBP offspring, while only two had also QP offspring. Eleven females were assigned maternity of CBP offspring exclusively, while only two females were assigned maternity of QP offspring exclusively (Table 3).

There were $110(60.8 \%)$ socially monogamous males and 36 (19.9\%) cases of polygyny (males assigned as the main father of more than one nest). Polygynous males had nests that were relatively close to each other (median $=20.85 \mathrm{~m}$ ), within the same or the nearest trio (Figure 1). This distance is slightly higher than the median between-box distance within a trio $(16.58 \mathrm{~m}$, bootstrapping test, $P<0.05)$, and much lower $(P<0.001)$ than the median distance to the nearest trio $(85.56 \mathrm{~m})$ or a random distance within the colony $(299.8 \mathrm{~m})$.

The variation between years in the proportion of polygynous vs. monogamous males was marginally significant $\left(\chi^{2}=5.5\right.$, $\mathrm{df}=2, P=0.064)$. The incidence of polygyny was higher in 2004 with 16 polygynous males $(29.6 \%)$, progressively decreasing in 2005 and 2006 to $13(18.4 \%)$ and 7 (12.15\%) polygynous males, respectively. The level of polygyny was also higher in 2004, with males having up to four nests; in 2005 the maximum number of nests per male was three, while in 2006 it was two. Among the nests with identified fathers 37 (56.1\%), 27 (39.7\%), and 14

TABLE 2 | The number of males and females with assigned parentage; in just 1 year; in all of the 3 years of the study; in consecutive and not consecutive years; and in total.

\begin{tabular}{lccc}
\hline & Fathers & Mothers & Same pair \\
\hline Parents in only 1 year & 62 & 63 & \\
Parents in all of the 3 years & 18 & 12 & 0 \\
Parents in 2004-2005 & $34^{\mathrm{a}}$ & $38^{\mathrm{a}}$ & 12 \\
Parents in 2005-2006 & $33^{\mathrm{a}}$ & $33^{\mathrm{a}}$ & $7^{\mathrm{b}}$ \\
Parents in 2004, 2006 & $19^{\mathrm{a}}$ & $16^{\mathrm{a}}$ & 0 \\
Total no. of individual parents & 112 & 125 & \\
\hline
\end{tabular}

aparents identified in all 3 years are also included in these figures. ${ }^{b}$ Two of these pairs shared one male.

TABLE 3 | Females that were assigned either as the main mother of a clutch, or as just having CBP or QP offspring.

\begin{tabular}{|c|c|c|c|c|c|c|}
\hline \multirow[t]{2}{*}{ Year } & \multirow{2}{*}{$\begin{array}{c}\text { Females } \\
\text { assigned as } \\
\text { mothers }\end{array}$} & \multicolumn{3}{|c|}{ Main Mother of the Clutch } & \multirow[t]{2}{*}{ Just CBP } & \multirow[t]{2}{*}{ Just QP } \\
\hline & & Total & + CBP & $+Q P$ & & \\
\hline \multirow[t]{2}{*}{2004} & 65 & 64 & 3 & 0 & 1 & 0 \\
\hline & & $98.46 \%$ & & & $1.54 \%$ & $0.00 \%$ \\
\hline \multirow[t]{2}{*}{2005} & 70 & 59 & $7^{a}$ & 3 & $9^{b}$ & 1 \\
\hline & & $84.29 \%$ & & & $12.86 \%$ & $2.86 \%$ \\
\hline \multirow[t]{2}{*}{2006} & 54 & 53 & 7 & 0 & 1 & 1 \\
\hline & & $98.15 \%$ & & & $1.85 \%$ & $1.85 \%$ \\
\hline \multirow[t]{2}{*}{ Total } & $188^{d}$ & 176 & 17 & 3 & 11 & 2 \\
\hline & & $93.12 \%$ & & & $5.82 \%$ & $1.06 \%$ \\
\hline
\end{tabular}

Some of the females that had their own nest also had CBP chicks and QP chicks in other nests.

a One female had three chicks in these conditions. ${ }^{b}$ One female had two chicks in these conditions. 'This total is the sum of the number of mothers assigned per year, therefore it contains females repeated in different years. 

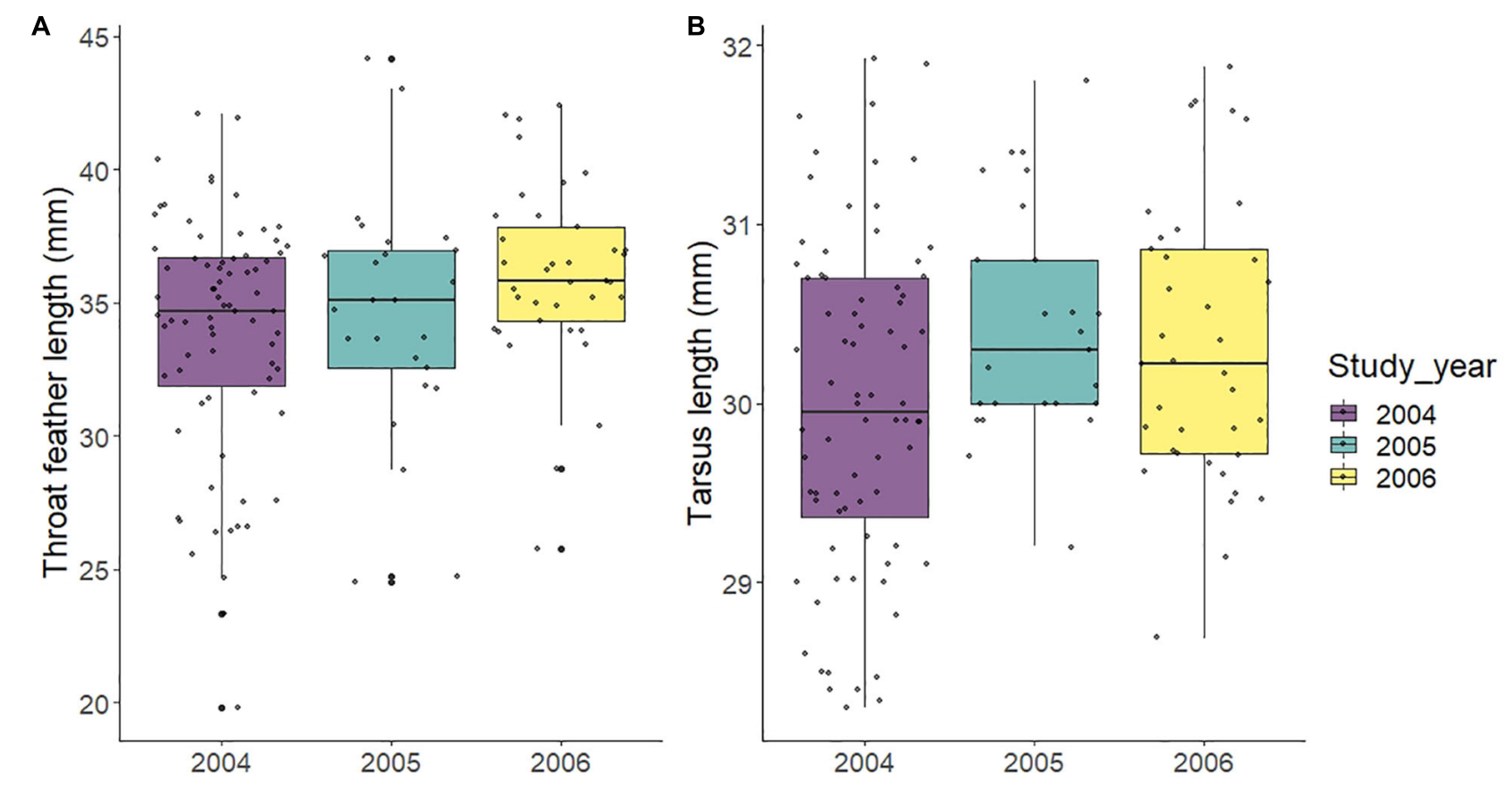

FIGURE 2 | Changes in male throat feather length (A) and tarsus length (B) across the 3 years of study. For the analysis and the figures, we took only one measurement per male. In case of males sampled in multiple years, only the first year was selected.

(25.9\%) were occupied by a polygynous male in 2004, 2005, and 2006, respectively. Therefore, there was a significant difference between years in the proportion of nests defended by polygynous males $\left(\chi^{2}=11.3, \mathrm{df}=2, P=0.004\right)$.

To estimate whether the quality or age of the males that arrived at the population changed as years passed, we analyzed the effect of year in two dimorphic male traits, namely tarsus length and ornamental feather length. To avoid the confounding effect of a possible longitudinal change in traits, we performed the analysis using only one datum per bird, namely that recorded in their first capture. These models showed that both tarsus length and feather length increased as years passed [LM tarsus length: $F=6.65$, $\mathrm{df}=1,130, P=0.011$, estimate $(\mathrm{SE})=0.19(0.07)$; LM feather length: $F=7.94$, df $=1,129, P=0.006$, estimate $(\mathrm{SE})=1.15(0.40)$; Figure 2].

\section{Extra-Pair Paternity}

Paternity was assigned to 181 different males. Of these, 14 males (7.7\%) were assigned solely as fathers of CBP chicks and 21 males (11.6\%) were identified exclusively as the father of EPP offspring. The remaining $146(80.7 \%)$ were assigned as the main father of one or more clutches, with some of them siring also CBP or EPP chicks (Table 4).

Out of the 110 socially monogamous males, nine sired additional CBP offspring and 15 sired additional EPY. Seven of the 36 polygynous males also sired at least one CBP chick and another two sired EPP offspring (Table 4). The distance between the main nest and the nests where EPY from the same male were found was relatively short (median: $109.2 \mathrm{~m}$ ). This distance is, however, larger than those to other boxes of the same or nearest trio, but closer than random distances within the colony (bootstrapping tests, all $P<0.001$, Figure 1).

There were 66 broods (19.4\%) with one or more EPY, amounting a total of $86 \mathrm{EPY}(7.0 \%)$. The proportion of nests with EPP was not significantly different between years (8.0 vs. $6.7 \%$ and $6.4 \%$ in 2004, 2005, and 2006, respectively; $\chi^{2}=0.88, \mathrm{df}=2$, $P=0.65)$.

\section{Conspecific Brood Parasitism and Quasi-Parasitism}

There were 90 cases ( $7.4 \%$ of the chicks) of intra-specific brood parasitism (CBP) detected in 72 clutches (21.1\%). The proportion of CBP offspring varied greatly between years $\left(\chi^{2}=12.1, \mathrm{df}=2\right.$, $P=0.002$ ). CBP increased from a mere $3.9 \%$ of the genotyped offspring in $11.1 \%$ of the clutches in 2004 , to 10.0 and $8.4 \%$ of the offspring and 25.5 and $28.6 \%$ of the clutches, in 2005 and 2006, respectively (Table 5).

Both parents were assigned to $24(26.7 \%)$ of the parasitic chicks and additional information was available for 15 of these 24 pairs. In nine of these, the pair that sired the CBP chick had a nest close to the parasitized one (Figure 1) and the laying dates of both nests overlapped (with the first eggs been laid in average $1.0 \pm 1.1$ days apart). However, these parasitic parents lost the eggs in their main nest (predation or same-species boycott), proceeding to lay a second clutch some days later. In another three cases, the parasitic couples had had a first clutch in their own nest, and then laid an egg of their second clutch in a neighboring nest in addition to the others laid in their own nest. 
TABLE 4 | Males that were assigned either as the main fathers of a clutch, or as just having fathered CBP or EPP offspring.

\begin{tabular}{|c|c|c|c|c|c|c|c|c|c|c|}
\hline \multirow[t]{3}{*}{ Year } & \multirow{3}{*}{$\begin{array}{c}\text { Males assigned as } \\
\text { fathers }\end{array}$} & \multicolumn{7}{|c|}{ Main father of the clutch } & \multirow[t]{3}{*}{ Just parasitic males } & \multirow{3}{*}{$\begin{array}{c}\text { Just extra-pair } \\
\text { fathers }\end{array}$} \\
\hline & & \multirow[t]{2}{*}{ Total } & \multicolumn{3}{|c|}{ Socially monogamous } & \multicolumn{3}{|c|}{ Socially polygamous } & & \\
\hline & & & Total & $+\mathrm{CBP}$ & +EPP & Total & $+\mathrm{CBP}$ & +EPP & & \\
\hline 2004 & 54 & $\begin{array}{c}45 \\
(83.33 \%)\end{array}$ & $\begin{array}{c}29 \\
(53.7 \%)\end{array}$ & 0 & 1 & $\begin{array}{c}16^{\mathrm{c}} \\
(29.63 \%)\end{array}$ & 2 & 0 & $1(1.85 \%)$ & $\begin{array}{c}8 \\
(14.81 \%)\end{array}$ \\
\hline 2005 & 69 & $\begin{array}{c}54 \\
(78.26 \%)\end{array}$ & $\begin{array}{c}41 \\
(59.42 \%)\end{array}$ & $6^{a}$ & $8^{a}$ & $\begin{array}{c}13^{d} \\
(18.84 \%)\end{array}$ & $4^{a}$ & 2 & $7^{\mathrm{a}}(10.14 \%)$ & $\begin{array}{c}8 \\
(11.59 \%)\end{array}$ \\
\hline 2006 & 58 & $\begin{array}{c}47 \\
(81.03 \%)\end{array}$ & $\begin{array}{c}40 \\
(68.96 \%)\end{array}$ & $3^{b}$ & $6^{a, b}$ & $\begin{array}{c}7^{e} \\
(12.07 \%)\end{array}$ & 1 & 0 & $6(10.34 \%)$ & $\begin{array}{c}5 \\
(8.62 \%)\end{array}$ \\
\hline Total & $181^{f}$ & $\begin{array}{c}146 \\
(80.66 \%)\end{array}$ & $\begin{array}{c}110 \\
(60.77 \%)\end{array}$ & 9 & 15 & $\begin{array}{c}36 \\
(19.89 \%)\end{array}$ & $7^{a}$ & 2 & $14^{\mathrm{a}}(7.73 \%)$ & $\begin{array}{c}21 \\
(11.6 \%)\end{array}$ \\
\hline
\end{tabular}

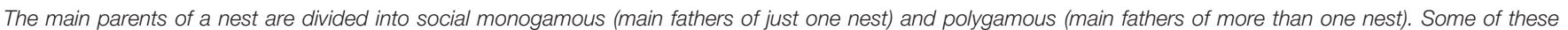
monogamous and polygamous males also sired CBP chicks and EPP chicks in other nests.

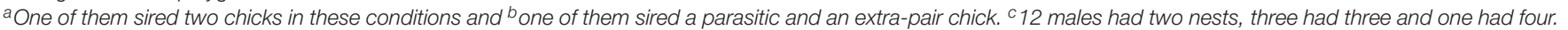

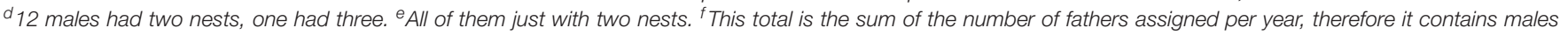
repeated in different years.

TABLE 5 | Occurrence of EPP, CBP, and QP detected in each of the studied years and in total.

\begin{tabular}{|c|c|c|c|c|c|c|c|c|c|}
\hline \multirow[t]{2}{*}{ Year } & \multirow{2}{*}{$\frac{\text { No. chicks }}{\text { No. broods }}$} & \multicolumn{2}{|c|}{ Extra-Pair Paternity (EPP) } & \multicolumn{4}{|c|}{ Intra-specific Brood Parasitism (CBP) } & \multicolumn{2}{|c|}{ Quasi Parasitism (QP) } \\
\hline & & Total & Known father & Total & Known mother & Known father & Both parents known & Total & Known mother \\
\hline \multirow[t]{2}{*}{2004} & 432 & $\begin{array}{c}29 \\
(6.7 \%)\end{array}$ & $\begin{array}{c}8 \\
(27.6 \%)\end{array}$ & $17(3.9 \%)$ & $3(17.7 \%)$ & $\begin{array}{c}2 \\
(11.8 \%)\end{array}$ & $\begin{array}{c}2 \\
(11.8 \%)\end{array}$ & $1(0.2 \%)$ & 0 \\
\hline & 126 & $\begin{array}{c}23 \\
(18.3 \%)\end{array}$ & $\begin{array}{c}8 \\
(34.8 \%)\end{array}$ & $14(11.1 \%)$ & $2(14.3 \%)$ & $\begin{array}{c}2 \\
(14.3 \%)\end{array}$ & $\begin{array}{c}2 \\
(14.3 \%)\end{array}$ & $1(0.8 \%)$ & 0 \\
\hline \multirow[t]{2}{*}{2005} & 401 & $\begin{array}{c}32 \\
(8.0 \%)\end{array}$ & $\begin{array}{c}24 \\
(75.0 \%)\end{array}$ & 40(10.0\%) & $5(12.5 \%)$ & $\begin{array}{c}4 \\
(10.0 \%)\end{array}$ & $\begin{array}{c}14 \\
(35.0 \%)\end{array}$ & $10(2.5 \%)$ & $\begin{array}{c}4 \\
(40.0 \%)\end{array}$ \\
\hline & 110 & $\begin{array}{c}23 \\
(20.9 \%)\end{array}$ & $\begin{array}{c}19 \\
(83.0 \%)\end{array}$ & $28(25.5 \%)$ & $3(10.7 \%)$ & $\begin{array}{c}3 \\
(10.7 \%)\end{array}$ & $\begin{array}{c}13 \\
(46.4)\end{array}$ & $8(7.3 \%)$ & $\begin{array}{c}4 \\
(50.0 \%)\end{array}$ \\
\hline \multirow[t]{2}{*}{2006} & 392 & $\begin{array}{c}25 \\
(6.4 \%)\end{array}$ & $\begin{array}{c}14 \\
(56.0 \%)\end{array}$ & $33(8.4 \%)$ & 0 & $\begin{array}{c}3 \\
(9.1 \%)\end{array}$ & $\begin{array}{c}8 \\
(24.2 \%)\end{array}$ & $1(0.3 \%)$ & $\begin{array}{c}1 \\
(100.0 \%)\end{array}$ \\
\hline & 105 & $\begin{array}{c}20 \\
(19.1 \%)\end{array}$ & $\begin{array}{c}13 \\
(65.0 \%)\end{array}$ & $30(28.6 \%)$ & 0 & $\begin{array}{c}3 \\
(10.0 \%)\end{array}$ & $\begin{array}{c}8 \\
(26.7 \%)\end{array}$ & $1(1.0 \%)$ & $\begin{array}{c}1 \\
(100.0 \%)\end{array}$ \\
\hline \multirow[t]{2}{*}{ Total } & 1225 & $\begin{array}{c}86 \\
(7.0 \%)\end{array}$ & $\begin{array}{c}46 \\
(53.5 \%)\end{array}$ & $90(7.4 \%)$ & $8(8.9 \%)$ & $\begin{array}{c}9 \\
(10.0 \%)\end{array}$ & $\begin{array}{c}24 \\
(26.7 \%)\end{array}$ & $12(1.0 \%)$ & $\begin{array}{c}5 \\
(41.7 \%)\end{array}$ \\
\hline & 341 & $\begin{array}{c}66 \\
(19.4 \%)\end{array}$ & $\begin{array}{c}40 \\
(60.6 \%)\end{array}$ & $72(21.1)$ & $5(6.9 \%)$ & $\begin{array}{c}8 \\
(11.1 \%)\end{array}$ & $\begin{array}{c}23 \\
(31.9 \%)\end{array}$ & $10(2.9 \%)$ & $\begin{array}{c}5 \\
(50.0 \%)\end{array}$ \\
\hline
\end{tabular}

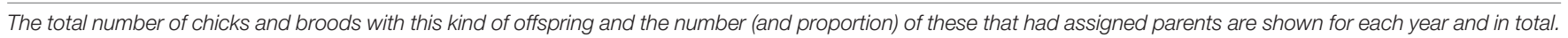

In a further case, the couple that laid the parasitic egg during the first clutch went on to lay a whole clutch in the same nest where they were parasitic before. In two additional cases the parasitic female had sired a whole clutch in the first clutch, but for the second clutch she had been replaced by a new female, and she laid a parasitic egg in the same nest, sired by a new male. Despite these cases of high proximity between nests, the median distance between the main nest and the nest with CBP from the same female was $122.7 \mathrm{~m}$; this distance is farther than that to the nearest trio, although some points overlap with it, but closer than random distances within the colony (bootstrapping tests, all $P<0.001$, Figure 1). In the case of CBP following nest loss, the distance was shorter (median: $74.5 \mathrm{~m}$ ), similar to that to the nearest trio $(P=0.056)$.

In addition to the detection of CBP chicks, cases of quasiparasitism were also detected (offspring that shared the father but not the mother with their brood mates). Twelve (0.98\%) offspring were found in $10(2.93 \%)$ clutches to be quasi-parasites (Table 5). The number of QP offspring varied significantly between years $\left(\chi^{2}=14.1, \mathrm{df}=2, P=0.001\right)$; ten occurred in 2005 , while in each of 2004 and 2006 just one was found.

We were able to identify the mother of five of the QP offspring. In two of these cases the female had not been assigned any additional offspring. In one case, the female had a brood in the same nest in which she later laid the QP egg. By then, the male defending the nest was the same, but the main mother of this second brood changed. For another QP case the order was reversed: the mother of the QP offspring in the first clutch became the main mother of the second clutch in the same nest. Finally, in the other QP case, the mother of the QP offspring had, simultaneously, a brood in a neighboring nest with another male. 


\section{DISCUSSION}

Variation in avian reproductive strategies is typically visualized from a comparative standpoint, since different taxa differ greatly in the degree of polygyny, EPP or intra-specific brood-parasitism (Griffith et al., 2002; Westneat and Stewart, 2003; Yom-Tov and Geffen, 2017; Brouwer and Griffith, 2019). This perspective has led to the identification of some species-specific ecological, morphological and life-history traits that are associated with reproductive strategies (Arnold and Owens, 2002; Spottiswoode and Møller, 2004; Botero and Rubenstein, 2012; Yom-Tov and Geffen, 2017; but see: Brouwer and Griffith, 2019). In contrast, our study allows us to examine the temporal plasticity of these strategies, following a single population from the year of colony formation to 2 years later. Parentage data from these years provide us with important data on how polygyny decreases with time, likely as a consequence of increasing recruits and immigrants. In parallel to this change, we found an increase in CBP and QP. Given that the majority of the extra-pair males or parasitic females could not be assigned to the breeding population, we interpret these patterns as consequences of an increase of floaters with time. These floaters are expected to pursue a mixture of mating strategies to be able to succeed in the population (Evans, 1988; Sandell and Diemer, 1999; Veiga et al., 2001; Asawaka and Saitou, 2006). This perspective emphasizes how behavioral patterns are plastic traits that vary with time, tracking changes in density and social structure.

We used two different programs, NEWPAT XL (Wilmer et al., 1999) and CERVUS 3.0.3 (Marshall et al., 1998; Kalinowski et al., 2007) to assign parentage and corroborated the parentage with observational data. We believe that taking this conservative approach to the parentage assignment provided us with highly reliable data. However, as a result, not every chick had parents assigned, which may have led to a slight underestimation of the levels of EPP, CBP, and QP.

The parentage data allowed the calculation of levels of rapid mate switching (change of social partners within a year) and mate retention (maintaining the same social partner between years). It is interesting to see that in the cases where just one of the parents changed between clutches, females were twice as likely to have changed as males. Using these data, we can also infer a high divorce rate with only 19 pairs breeding together for more than 1 year. However, the real divorce rate is difficult to establish, since we do not know how often mate switching is due to the death of one of the mates. The high level of rapid mate switching and low level of mate retention reinforces the need to use molecular methods for parentage assignment.

The degree of polygyny varied considerably during the 3 years of this study. The highest levels of polygyny were observed in 2004, when the colony was first established, with almost $30 \%$ of all fathers being polygynous and occupying almost half of the nest boxes (37 out of 77). By 2006 the proportion of polygynous fathers went down from 30 to $12 \%$. Prior to the installation of the nest boxes the availability of nest sites for this species (natural holes in trees and walls) was considerably lower. The age of the colony (time since the introduction of nest boxes in the area in 2004) comes up as a strong predictor of the change in mating strategies. What may have changed in these years? We believe that the most likely explanation is the number of recruits attempting to settle in the newly available nesting sites. Numerous studies show that floaters visit future breeding areas, and that prospecting behavior is widespread in passerines, mostly in their first year of life (Zack and Stutchbury, 1992; Danchin et al., 2004; Moreno, 2016). Following this logic, the number of available nest sites in a given year may influence the number of individuals visiting the area the following year. We believe that the number of individuals arriving to breed in the area and competing for nest sites may have increased year after year. This is to be expected given the high philopatry of this species. Previous studies in this same species show that prospectors are attracted to successful broods at the nestling stage (Parejo et al., 2008; Veiga et al., 2013), which suggests that they might be collecting public information on breeding success. Lower levels of male-male competition at the beginning of the study would explain why more males managed to defend several nests in 2004, but their number dropped progressively in consequent years. In support of this explanation, we found that male feather length and body size increased with years passed, suggesting that the colony was initially founded by younger, less competitive males. Counterintuitively, polygyny decreased when male quality increased in 2005 and 2006, suggesting that the operational sex ratio of suitable partners also changed with time. Unfortunately, we do not have data on the floater population size, but we assume that this population increased in size as years passed, thus increasing competition for nest boxes, not only because a greater number of males visited the boxes, but also because the average quality of these males was higher (Figure 2). Therefore, the decrease in polygyny could be explained by an increase in the number of highly competitive males managing to defend nests and breed as years passed. Similarly, Veiga et al. (2001) also reported a decrease in polygyny with year (1996-1998) in a similar nest-box colony (Villalba, $50 \mathrm{~km}$ from our site) established between 1994 and 1995. They also report that the number of occupied nest boxes was low in the first years, but increased over the time until the boxes were fully occupied. This seems to mirror the pattern of increasing population density with colony age that we propose here. In the case of our study, the nest boxes were fully occupied from year one, perhaps reflecting a higher starting density at our site. Moreover, the percentage of polygynous males in 1996 and 1997 in the Villalba colony was much larger (over 75\%: calculated using published data; Cordero et al., 2001, 2003). So it seems that in the Villalba colony the lower density and, therefore, lower competition enabled more males to become polygynous. In contrast, the higher breeding density at our colony enabled fewer males to become polygynous and, as the density increased, this percentage decreased further. In any case, comparisons are difficult given the differences between sites in the way that boxes are placed.

The age of the colony and the likely increase in density did not affect the proportion of EPP. The slightly higher proportion of EPP found in 2005 (8.0 vs. 6.7\% and 6.4\% in 2004 and 2006, respectively) could be explained by the higher percentages of chicks with at least one assigned parent in that season $(94.0 \%$ 
in 2005 vs. 85.2 and $75.8 \%$ in 2004 and 2006, respectively), thus increasing the probability of detecting EPP.

The average proportion of EPY (7.0\%) detected in this study is lower than the rate (10-20\%) reported by Cordero et al. (2003). The difference in estimates may be due to their considering only nests for which they knew the social father (true father of most of the brood) whereas we estimated the percentage of EPY from all genotyped offspring. Therefore, the $7.0 \%$ of EPP reported in our study is likely to be an underestimate.

The proportion of CBP offspring in 2005 and 2006 was more than double that of 2004 (25.5 and $28.6 \%$ of the nests parasitized in 2005 and 2006, respectively and only $11.1 \%$ in 2004). This significantly lower rate of CBP during the first year is most likely linked to the age of the colony, and proposed increase in density. Similar patterns have been observed in the European starling (S. vulgaris) for which the percentage of CBP chicks changed from 14 to $27 \%$ in 25 and $64 \%$ of the nests in two consecutive years (Loyau et al., 2005). It has been proposed that CBP could be a strategy employed by floaters (Evans, 1988; Asawaka and Saitou, 2006). A higher density of individuals in the second and third years is likely to have produced an increase in the number of floaters and could, therefore, explain the increase on CBP.

Cordero et al. (2003), found an extremely low level of CBP ( $1 \%$ of the broods) compared with the levels found in this study (21\%) and the similarly high levels (12 and 37\%) reported by Calvo et al. (2000). This disparity could be due to the accuracy of the technique used. DNA fingerprinting (as used by Cordero et al., 2003) carries a high probability of mistaking the true parent with a genetically similar individual. Furthermore, they apparently considered chicks as EPP when they did not match the social father, even when the mother was unknown. This may have artificially increased the number of cases of EPP and reduced the cases of CBP. Conversely, Calvo et al. (2000) used only observational data to detect CBP. The use of microsatellite genetic data in this study (with the support of observational data) gave us a high reliability of our parentage assignment. However, while all the cases considered in this study as EPP, CBP, and QP (see below) are almost certainly assigned correctly, there may be cases in our study where EPP and CBP were not detected. The latter is very likely in nests where the main parents could not be assigned due to a lack of observational data.

Distances between pairs of nests defended by the same male were smaller than random, but not as close as contiguous nests, as expected by the compromise between male-nest defense and avoidance of female-female aggression (Sandell and Smith, 1996). Distances between the main nest and that in which EPP and CBP by the same birds were recorded were typically larger than those to immediate nest sites, but not too far either, suggesting that starlings have restricted geographical mobility within the colony and use local information nearby to acquire additional breeding resources. Although the boxes were not uniformly distributed, and their clustered disposition may somehow affect these findings, data show that birds avoided nests in close proximity to attract secondary females, or obtain EPP or CBP offspring, suggesting that alternative mating tactics are constrained by conspecifics (Slagsvold and Lifjeld, 1994).
Our study also contributes rare information to the limited number of studies that, in addition to reporting frequencies of $\mathrm{CBP}$, provide life history details that can be used to support and distinguish between the four main hypotheses for the adaptive benefits of CBP (described in the introduction). We found evidence for both of the hypotheses explaining the use of CBP by nesting females (the "nest loss" and "side payment" or "reproductive enhancement" hypotheses). Nine of the CBP eggs were sired by a couple that lost a clutch in their own nest. In all these cases, the laying days of parasitized and lost clutches overlapped. Also, in all nine cases the couples laid a replacement clutch some days later. It appears that females that lost their clutches near the end of egg-laying (e.g., when they had already laid all but one of the eggs of the clutch), resorted to lay the last egg(s) in a neighboring nest at a similar stage of incubation. This way, the parasitic egg had a chance to develop and the couple could lay a whole replacement clutch, instead of caring for only one offspring. Calvo et al. (2000) found that the number of nests parasitized was higher when nest failures were also more frequent. However, they were not able to identify the parasitic females and could not confirm that this relationship was direct. We found an increase in CBP in 2005 and 2006 with respect to 2004. The proposed increase in density with the age of the colony would also confer an increase in competition and this could have resulted in an increase in the number of lost clutches, due to same-species boycott. Therefore, the incidence of CBP would be increased indirectly.

We detected three cases in which a part of a second clutch was laid in another nest. The mortality rate among chicks of second clutches, at least in this area, tends to be higher due to the lack of food and water, and increased ambient temperature later in the year (Gil et al., 2008). Data from this population also confirms that brood reduction is common in second broods (Muriel et al., 2019). Splitting the clutch in two nests is a strategy by which some females would give some eggs the opportunity to develop and survive, while increasing the probability of survival of the offspring in their own nest. Therefore, these cases support the "side payment" or "reproductive enhancement" hypothesis. Evidence for this hypothesis has only been found for 15 bird species, most of them in the Anatidae and Rallidae (seven and three species, respectively; data from Lyon and Eadie, 2017).

From the 28 females identified as parasitic, we assume that 13 were floaters (non-nesting). The possibility of these birds having a nest in a natural hole cannot be eliminated, but it seems unlikely that this is the case for all females given the low number of natural nests and the fact that we found very few cases of "split" clutches (see above). Moreover, the mothers of 58 of the parasitic offspring could not be identified. The most likely explanation is that those mothers were non-nesting females and therefore were not captured and genotyped. This scenario would suggest that CBP was being used as a strategy by floaters. Even if in the majority of the cases we cannot distinguish between the "lifelong specialist parasite" and the "best of a bad job" hypotheses, it seems improbable that $\mathrm{CBP}$ was used as a lifelong strategy. Furthermore, we identified a couple that laid a parasitic egg during the first clutch and then had a whole clutch in this same nest where they were previously parasitic, and we found two cases where females 
sired whole clutches in the first reproductive clutch, but for the second clutch exhibited CBP. These findings show that, at least in some cases, CBP is used as a "best of a bad job" strategy by individuals that also have their own nest at other times. Previous studies in the closely related European starling ( $S$. vulgaris) also show that CBP as a phenomenon stems from diverse situations, suggesting that, at least in this genus, a single explanation is not sufficient (Evans, 1988).

The number of QP offspring identified was low (12 cases, $0.98 \%$ of the offspring). What is surprising is that 10 out of the 12 identified cases occurred in just one of the 3 years (2005). This may be in part the result of a higher rate of successful parentage assignment for that season, which would have allowed more cases to be identified. However, we believe that the proposed increase in density between 2004 and 2005 may have also contributed to a higher rate of QP by increasing the number of floaters and the incidence of rapid mate switches.

The two cases where the QP females were floaters and the two cases where the QP females had a full clutch in the parasitized nest before or after laying the QP egg, support the hypothesis that QP sometimes arises as an artifact of high levels of CBP, EPP and rapid mate switching (Griffith et al., 2004; Lyon and Eadie, 2017). The case of the QP female that simultaneously had her own nest with another male could be argued to support QP being a strategy per se. It is impossible for us to determine if the QP female gained access to that nest by mating with that male. However, it is interesting that none of the offspring in her own nest were fathered by the male fathering her QP offspring.

In conclusion, the use of molecular markers and observations to follow this spotless starling colony has allowed us to detect and quantify a great variety of reproductive strategies. We found evidence that points towards the existence of a high rate of mate switching and divorce in this species. We also observed a change in the prevalence of different reproductive strategies across years. In 2004, the year that the colony was first established, the level and the degree of polygyny were higher than in the two subsequent years. The decrease in polygyny coincided with an increase of CBP and QP. We propose that in 2004, being a new site, fewer individuals may have arrived in the area and competed for nest sites than in subsequent years. Furthermore, this increase in density and competition for nests and for mates resulted in a decreased incidence of polygyny and an increased incidence of alternative reproductive strategies like CBP and QP. Moreover, we managed to determine aspects of the life history of some of the parasitic females that show that both nesting and non-nesting (floaters) females engage in CBP. Strong evidence was also found for the "nest loss", the "reproductive enhancement" and the "best of a bad job" hypotheses for the adaptive basis of CBP.

\section{REFERENCES}

Aparicio, J. M., Cordero, P. J., and Veiga, J. P. (2001). A test of the hypothesis of mate choice based on heterozygosity in the spotless starling. Anim. Behav. 62, 1001-1006. doi: 10.1006/anbe.2001.1840

Arnold, K. E., and Owens, I. P. F. (2002). Extra-pair paternity and egg dumping in birds: life history, parental care and the risk of retaliation.

\section{DATA AVAILABILITY STATEMENT}

The original contributions presented in the study are included in the article/supplementary material, further inquiries can be directed to the corresponding author/s.

\section{ETHICS STATEMENT}

The animal study was reviewed and approved by Permission to work in the area, capture birds and collect blood samples was granted by permits from the Parque Regional del Alto Manzanares (Consejería de Medio Ambiente de la Comunidad Autónoma de Madrid) (Ref. 10/129049.9/11) and the city council of Soto del Real. At the time of this study (2004-2006) our manipulation did not require an experimentation permit under Spanish law.

\section{AUTHOR CONTRIBUTIONS}

PC and DG conducted the fieldwork. PC and JG conducted the laboratory work. PC wrote the manuscript in close collaboration with the two co-authors. All authors contributed to the article and approved the submitted version.

\section{FUNDING}

Finance for fieldwork and labwork was provided by a grant to DG from the Spanish Ministry of Science (BOS2002-00105), and DG was recipient of another grant from the same source while writing this study (CGL2017-83843-C2-1-P). PC was funded by a Ph.D. grant from CONACYT (México).

\section{ACKNOWLEDGMENTS}

Concepción Salaberría, Irene Espinosa, Kinga Deptuch, Janine Kamps, and Isabel López-Rull provided invaluable help during fieldwork. Juan Moreno and Pablo Veiga provided comments to the first version of the manuscript. Gordon S. Brown assisted with editing the manuscript. We are grateful to the two referees and the Frontiers editor for their valuable comments to an earlier version of the manuscript. This study is a contribution to the research developed at "El Ventorrillo" field station.

Proc. R. Soc. Lond. Ser. B Biol. Sci. 269, 1263-1269. doi: 10.1098/rspb.2002. 2013

Asawaka, M., and Saitou, T. (2006). Composition of breeding population in the grey starling (Sturnus cineraceous). J. Yamashina Inst. Ornithol. 38, 1-13. doi: 10.3312/jyio.38.1

Baeyens, G. (1981). Functional aspects of serial monogamy. Ardea 69, $145-166$. 
Berger, I., Dvir, Y., Leshem, Y., Yom-Tov, Y., and Markman, S. (2014). Extra-pair copulations, intra-specific brood parasitism, and quasi-parasitism in birds: a theoretical approach. Acta Ethol. 17, 131-140. doi: 10.1007/s10211-013-0170-4

Birkhead, T. R., and Møller, A. P. (1998). Sperm Competition and Sexual Selection. London: Academic Press.

Botero, C. A., and Rubenstein, D. R. (2012). Fluctuating environments, sexual selection and the evolution of flexible mate choice in birds. PLoS One 7:e32311. doi: 10.1371/journal.pone.0032311

Brouwer, L., and Griffith, S. C. (2019). Extra-pair paternity in birds. Mol. Ecol. 28, 4864-4882. doi: 10.1111/mec.15259

Calvo, J. M., Pascual, J. A., Deceuninck, B., and Peris, S. J. (2000). Intraspecific nest parasitism in the Spotless Starling Sturnus unicolor. Bird Study 47, 285-294. doi: 10.1080/00063650009461188

Celis, P., Gil, D., and Graves, J. A. (2007). Isolation and characterization of polymorphic microsatellites isolated from the spotless starling (Sturnus unicolor) and cross-species amplification in the European starling (Sturnus vulgaris). Mol. Ecol. Notes 7, 251-253. doi: 10.1111/j.1471-8286.2006.01571.x

Cordero, P. J., Aparicio, J. M., and Veiga, J. P. (2004). Parental genetic characteristics and hatching success in the spotless starling. Sturnus unicolor. Anim, Behav. 67, 637-642. doi: 10.1016/j.anbehav.2003.06.005

Cordero, P. J., Veiga, J. P., Moreno, J., and Parkin, D. T. (2003). Extra-pair paternity in the facultatively polygynous spotless starling, Sturnus unicolor. Behav. Ecol. Sociobiol. 54, 1-6. doi: 10.1007/s00265-003-0603-6

Cordero, P. J., Viñuela, J., Aparicio, J. M., and Veiga, J. P. (2001). Seasonal variation in sex ratio and sexual egg dimorphism favouring daughters in first clutches of the spotless starling. J. Evol. Biol. 14, 829-834. doi: 10.1046/j.1420-9101.2001. 00320.x

Coulson, J. C. (1966). The influence of the pair-bond and age on the breeding biology of the kittiwake Gull Rissa tridactyla. J. Anim. Ecol. 35, 269-279. doi: $10.2307 / 2394$

Culina, A., Radersma, R., and Sheldon, B. C. (2015). Trading up: the fitness consequences of divorce in monogamous birds. Biol. Rev. 90, 1015-1034. doi: $10.1111 /$ brv. 12143

Danchin, E., Giraldeau, L. A., Valone, T. J., and Wagner, R. H. (2004). Public information: from nosy neighbors to cultural evolution. Science 305, 487-491. doi: 10.1126/science. 1098254

Dawson, D. A., Hanotte, O., Greig, C., Stewart, I. R., and Burke, T. (2000). Polymorphic microsatellites in the blue tit Parus caeruleus and their crossspecies utility in 20 songbird families. Mol. Ecol. 9, 1941-1944. doi: 10.1046/ j.1365-294x.2000.01094-14.x

Dubois, F., and Cézilly, F. (2002). Breeding success and mate retention in birds: a meta-analysis. Behav. Ecol. Sociobiol. 52, 357-364. doi: 10.1007/s00265-0020521-z

Eadie, J. M., and Fryxell, J. M. (1992). Density dependence, frequency dependence, and alternative nesting strategies in goldeneyes. Am. Nat. 140, 621-641. doi: $10.1086 / 285431$

Ens, B. J., Safriel, U. N., and Harris, M. P. (1993). Divorce in the long-lived and monogamous oystercatcher, Haematopus ostralegus: incompatibility or choosing the better option? Anim. Behav. 45, 1199-1217. doi: 10.1006/anbe. 1993.1142

Evans, P. G. H. (1988). Intraspecific nest parasitism in the European starling Sturnus vulgaris. Anim. Behav. 36, 1282-1294. doi: 10.1016/s0003-3472(88) 80197-0

Feare, C. J. (1991). Intraspecific nest parasitism in Starlings Sturnus vulgaris: effects of disturbance on laying females. Ibis 133, 75-79. doi: 10.1111/j.1474-919X. 1991.tb04813.x

García-Vigón, E., Cordero, P. J., and Veiga, J. P. (2008). Exogenous testosterone in female spotless starlings reduces their rate of extrapair offspring. Anim. Behav. 76, 345-353. doi: 10.1016/j.anbehav.2008.01.019

Geffen, E., and Yom-Tov, Y. (2001). Factors affecting the rates of intraspecific nest parasitism among Anseriformes and Galliformes. Anim. Behav. 62, 1027-1038. doi: 10.1006/anbe.2001.1855

Gil, D., Bulmer, E., Celis, P., and López-Rull, I. (2008). Adaptive developmental plasticity in growing nestlings: sibling competition induces differential gape growth. Proc. R. Soc. Lond. . Ser. B Biol. Sci. 275, 549-554. doi: 10.1098/rspb. 2007.1360

Griffith, S. C., Lyon, B. E., and Montgomerie, R. (2004). Quasi-parasitism in birds. Behav. Ecol. Sociobiol. 56, 191-200. doi: 10.1007/s00265-004-0766-9
Griffith, S. C., Owens, I. P. F., and Thuman, K. A. (2002). Extra pair paternity in birds: a review of interspecific variation and adaptive function. Mol. Ecol. 11, 2195-2212. doi: 10.1046/j.1365-294X.2002.01613.x

Jacot, A., Valcu, M., and Kempenaers, B. (2010). Within-season divorce in Blue Tits (Cyanistes caeruleus). J. Ornithol. 151, 477-482. doi: 10.1007/s10336-0090483-2

Jones, A. G., and Ardren, W. R. (2003). Methods of parentage analysis in natural populations. Mol. Ecol. 12, 2511-2523. doi: 10.1046/j.1365-294X.2003.01928.x

Kalinowski, S. T., Taper, M. L., and Marshall, T. C. (2007). Revising how the computer program CERVUS accommodates genotyping error increases success in paternity assignment. Mol. Ecol. 16, 1099-1106. doi: 10.1111/j.1365-294X. 2007.03089.x

Lack, D. (1968). Ecological Adaptations for Breeding in Birds. London: Methuen.

Loyau, A., Moureau, B., Richard, M., Christe, P., Heeb, P., and Sorci, G. (2005). Cross-amplification of polymorphic microsatellites reveals extra-pair paternity and brood parasitism in Sturnus vulgaris. Mol. Ecol. Notes 5, 135-139. doi: $10.1111 / \mathrm{j} .1471-8286.2005 .00868 . \mathrm{x}$

Lyon, B. E., and Eadie, J. M. (2008). Conspecific brood parasitism in birds: a life-history perspective. Annu. Rev. Ecol. Evol. Syst. 39, 343-363. doi: 10.1146/ annurev.ecolsys.39.110707.173354

Lyon, B. E., and Eadie, J. M. (2017). "Why do birds lay eggs in conspecifics' nests?", in Avian Brood Parasitism, ed. M. Soler (Cham: Springer), 105-123. doi: 10.1007/978-3-319-73138-4_6

Marshall, T. C., Slate, J., Kruuk, L. E., and Pemberton, J. M. (1998). Statistical confidence for likelihood-based paternity inference in natural populations. Mol. Ecol. 7, 639-655. doi: 10.1046/j.1365-294x.1998.00374.x

Mayer, C., and Pasinelli, G. (2013). New support for an old hypothesis: density affects extra-pair paternity. Ecol. Evol. 3, 694-705. doi: 10.1002/ece3.489

Moreno, J. (2016). The unknown life of floaters: the hidden face of sexual selection. Ardeola 63, 49-77. doi: 10.13157/arla.63.1.2016.rp3

Muriel, J., Pérez-Rodríguez, L., and Gil, D. (2019). Age-related patterns of yolk androgen deposition are consistent with adaptive brood reduction in spotless starlings. Behav. Ecol. Sociobiol. 73, 1-12. doi: 10.1007/s00265-0192770-0

Parejo, D., Pérez-Contreras, T., Navarro, C., Soler, J. J., and Avilés, J. M. (2008). Spotless starlings rely on public information while visiting conspecific nests: an experiment. Anim. Behav. 75, 483-488. doi: 10.1016/j.anbehav.2007. 05.012

Petrie, M., and Kempenaers, B. (1998). Extra-pair paternity in birds: explaining variation between species and populations. Trends Ecol. Evol. 13, 52-58. doi: 10.1016/s0169-5347(97)01232-9

Petrie, M., and Møller, A. P. (1991). Laying eggs in others' nests: intraspecific brood parasitism in birds. Trends Ecol. Evol. 6, 315-320. doi: 10.1016/0169-5347(91) 90038

Petrželková, A., Michálková, R., Albrechtová, J., Cepák, J., Honza, M., Kreisinger, J., et al. (2015). Brood parasitism and quasi-parasitism in the European barn swallow Hirundo rustica rustica. Behav. Ecol. Sociobio. 69, 1405-1414. doi: 10. 1007/s00265-015-1953-6

Primmer, C. R., Møller, A. P., and Ellegren, H. (1996). A wide-range survey of cross-species microsatellite amplification in birds. Mol. Ecol. 5, 365-378. doi: 10.1046/j.1365-294X.1996.00092.x

R Core Team (2019). R: A Language and Environment for Statistical Computing. Vienna: R Foundation for Statistical Computing.

Sandell, M. I. (1998). Female aggression and the maintenance of monogamy: female behaviour predicts male mating status in European starlings. Proc. R. Soc, Lond. Ser. B Biol.Sci. 265, 1307-1311. doi: 10.1098/rspb.1998.0434

Sandell, M. I., and Diemer, M. (1999). Intraspecific brood parasitism: a strategy for floating females in the European starling. Anim. Behav. 57, 197-202. doi: 10.1006/anbe.1998.0936

Sandell, M. I., and Smith, H. G. (1996). Already mated females constrain male mating success in the European starling. Proc. R. Soc. Lond. Ser. B Biol. Sci. 263, 743-747. doi: 10.1098/rspb.1996.0111

Slagsvold, T., and Lifjeld, J. T. (1994). Polygyny in birds: the role of competition between females for male parental care. Am. Nat. 143, 59-94. doi: 10.1086/ 285596

Spottiswoode, C., and Møller, A. P. (2004). Extrapair paternity, migration, and breeding synchrony in birds. Behav. Ecol. 15, 41-57. doi: 10.1093/beheco/ $\arg 100$ 
Stoffel, M. A., Nakagawa, S., and Schielzeth, H. (2017). rptR: repeatability estimation and variance decomposition by generalized linear mixed-effects models. Methods Ecol. Evol. 8, 1639-1644. doi: 10.1111/2041-210X.12797

Stouffer, P. C., Kennedy, E. D., and Power, H. W. (1987). Recognition and removal of intraspecific parasite eggs by starlings. Anim. Behav. 35, 1583-1584. doi: 10.1016/s0003-3472(87)80040-4

Summers, K., and Amos, W. (1997). Behavioral, ecological, and molecular genetic analyses of reproductive strategies in the Amazonian dart-poison frog. Dendrobates ventrimaculatus. Behav. Ecol. 8, 260-267. doi: 10.1093/beheco/8. 3.260

Veiga, J. P., Moreno, J., Cordero, P. J., and Mínguez, E. (2001). Territory size and polygyny in the spotless starling: resource-holding potential or social inertia? Can. J. Zool. 79, 1951-1956. doi: 10.1139/z01-161

Veiga, J. P., Polo, V., Arenas, M., and Sánchez, S. (2013). Nest intrusions in relation to breeding status in the spotless starling. Behaviour 150, 1553-1566. doi: 10.1163/1568539x-00003109

Westneat, D. F., and Sherman, P. W. (1997). Density and extra-pair fertilizations in birds: a comparative analysis. Behav. Ecol. Sociobiol. 41, 205-215. doi: 10.1007/ s002650050381

Westneat, D. F., and Stewart, I. R. K. (2003). Extra pair paternity in birds: causes, correlates, and conflict. Annu. Rev. Ecol. Evol. Syst. 34, 365-396. doi: 10.1146/ annurev.ecolsys.34.011802.132439
Wilmer, J. W., Allen, P. J., Pomeroy, P. P., Twiss, S. D., and Amos, W. (1999). Where have all the fathers gone? An extensive microsatellite analysis of paternity in the grey seal (Halichoerus grypus). Mol. Ecol. 8, 1417-1429. doi: 10.1046/j.1365-294x.1999.00705.x

Yom-Tov, Y., and Geffen, E. (2017). "Conspecific brood parasitism among birds: the effects of phylogeny, mode of reproduction and geographic distribution," in Avian Brood Parasitism, ed. M. Soler (Cham: Springer), 95-103. doi: 10.1007/ 978-3-319-73138-4_5

Zack, S., and Stutchbury, B. J. (1992). Delayed breeding in avian social-systems: the role of territory quality and floater tactics. Behaviour 123, 194-219. doi: $10.1163 / 156853992 \times 00020$

Conflict of Interest: The authors declare that the research was conducted in the absence of any commercial or financial relationships that could be construed as a potential conflict of interest.

Copyright (C) 2021 Celis, Graves and Gil. This is an open-access article distributed under the terms of the Creative Commons Attribution License (CC BY). The use, distribution or reproduction in other forums is permitted, provided the original author(s) and the copyright owner(s) are credited and that the original publication in this journal is cited, in accordance with accepted academic practice. No use, distribution or reproduction is permitted which does not comply with these terms. 